\title{
Daerah penangkapan ikan dari kapal huhate yang berpangkalan di Pelabuhan Perikanan Pantai Belang
}

\author{
Fishing ground of pole and liner based in Belang Coastal Fishing Port \\ DEDY SUPRIANTO*, EMIL REPPIE dan JOHNNY BUDIMAN \\ Program Studi Pemanfaatan Sumberdaya Perikanan, Fakultas Perikanan dan Ilmu Kelautan, \\ Universitas Sam Ratulangi, Manado 95115
}

\begin{abstract}
Skipjack (Katsuwonus pelamis) is a leading economic activity in the fisheries sector of the North Sulawesi, commonly captured by pole and line fishing gear. To improve the fishing efficiency with the gear, it is indispensible to know the distribution of fishing ground and fishing seasons. This study was aimed describing the pole and line fishing gear and its fishing process, mapping the position of skipjack fishing ground landed in Belang Coastal Fishing Port, and predicting the skipjack fishing season, by using a descriptive method. Primary data gained by interviews and direct measurement techniques to know the position of fishing ground during fishing operation, supported by secondary data. Position data of skipjack catches landed at Belang port was plot on the base map as a thematic map. Fishing season was analyzed by comparing the average monthly catches and average total catches for the given year. Fishing ground of pole and line based in Belang Coastal Fishing Port for the year 2012 was situated in Moluccas Sea at geographical position $0^{0} 00^{\prime} 5.48^{\prime \prime} \mathrm{N}-1^{0} 16^{\prime} 2.12^{\prime \prime} \mathrm{N}$ and $124^{0} 04^{\prime} 5.48^{\prime \prime} \mathrm{E}-126^{0} 22^{\prime} 5.38^{\prime}$ ' E. Fishing season occurred in April for the first phase, then from July to September for the second phase, where the second phase is larger and longer.
\end{abstract}

Keywords: skipjack, pole and line, fishing ground, fishing season, Belang, North Sulawesi

\begin{abstract}
ABSTRAK
Ikan cakalang (Katsuwonus pelamis) merupakan suatu kegiatan ekonomi unggulan di sektor perikanan Sulawesi Utara, yang biasanya ditangkap dengan alat tangkap huhate. Untuk meningkatkan efisiensi penangkapan ikan dengan huhate, maka diperlukan pengetahuan tentang sebaran daerah penangkapan ikan dan musim penangkapannya. Penelitian bertujuan mendeskripsikan alat tangkap huhate dan proses penangkapannya; memetakan posisi daerah penangkapan cakalang yang didaratkan di Pelabuhan Perikanan Pantai Belang dan menduga musim penangkapan ikan cakalang, dengan metode deskriptif. Data primer diperoleh melalui wawancara dan pengukuran langsung untuk mengetahui posisi daerah penangkapan saat operasi, serta didukung dengan data sekunder. Data posisi tangkapan cakalang diplot dalam peta dasar menjadi peta tematik. Musim ikan dianalisis dengan membandingkan rata-rata hasil tangkapan bulanan dan rata-rata hasil tangkapan total pada tahun tersebut. Daerah penangkapan ikan dari kapal huhate yang berpangkalan di Pelabuhan Perikanan Pantai Belang selama tahun 2012 berada di perairan Laut Maluku pada posisi geografis $0^{0} 00{ }^{\prime} 5.48^{\prime \prime} \mathrm{U}-1^{0} 16{ }^{\prime} 2.12$ ' U dan $124^{0} 04^{\prime} 5.48^{\prime}$ ' $\mathrm{T}$ $126^{\circ} 22^{\prime} 5.38^{\prime \prime}$ T. Musim penangkapan ikan terjadi pada bulan April untuk fase pertama, kemudian pada bulan Juli sampai bulan September untuk fase kedua; tetapi fase kedua lebih besar dan lebih lama.
\end{abstract}

Kata-kata kunci: cakalang, huhate, daerah penangkapan, musim penangkapan, Belang, Sulawesi utara

\section{PENDAHULUAN}

Berdasarkan sebaran wilayahnya produksi perikanan Koridor Ekonomi Sulawesi merupakan wilayah yang memiliki produksi perikanan laut

\footnotetext{
* Alamat untuk penyuratan; email: dedysuprianto15@yahoo.com
}

terbesar. Yang berarti bahwa sektor perikanan merupakan salah satu kegiatan ekonomi utama di koridor ini (Anonimous, 2011).

Meskipun sumberdaya perikanan cukup melimpah, terdapat persoalan terkait dengan eksploitasi penangkapan ikan yang berlebihan di beberapa wilayah pantai laut, sehingga 
mengancam keberlanjutan kegiatan ini, sehingga diperlukan alat penangkap ikan yang ramah lingkungan memiliki kriteria selektivitas tinggi, hasil tangkapan sampingan rendah, tidak merusak lingkungan, tidak menangkap spesies yang dilindungi, pengoperasian alat tidak membahayakan nelayan, dan tidak beroperasi di daerah terlarang (Anonimous, 2008).

Namun demikian, secara khusus, dalam pengembangan kegiatan ekonomi utama perikanan ini, ada beberapa tantangan yang harus dihadapi, antara lain:

(1) Persaingan di pasar global, dimana beberapa produk perikanan dari negara lain seperti Thailand dan Vietnam memiliki daya saing yang sangat tinggi, dikarenakan proses produksi yang jauh lebih efisien dibandingkan Indonesia.

(2) Persaingan di pasar dalam negeri, yaitu daerah-daerah lainnya di Indonesia yang memproduksi produk perikanan sejenis.

(3) Persyaratan kualitas (mutu) produk perikanan seperti persyaratan label, kemasan, keamanan produk, traceability, green/eco label dan syarat kandungan bahan tambahan pangan akan semakin ketat. Ini merupakan suatu tantangan ke depan agar industri perikanan dapat lebih meningkatkan mutu dan memperketat kontrol kualitas produk perikanan yang dihasilkan.

Kenyataannya masyarakat lebih cenderung membeli bahan pangan dan hasil perikanan yang telah diolah dan dikemas dalam bentuk yang lebih mewah. Ini merupakan suatu tantangan dan sekaligus peluang usaha industri pengolahan hasil perikanan, misalnya pengembang inovasi produk siap saji, produk beku, produk kaleng, produk kering, dan value added seafood (fillet kakap, tuna loin steak).

Berdasarkan potensi dan tantangan pengembangan kegiatan perikanan tersebut di atas, maka diperlukan dukungan terkait regulasi dan kebijakan, antara lain:

1) Mengembangkan minapolitan berbasiskan perikanan tangkap untuk percepatan pembangunan kawasan yang berbasis perikanan tangkap dan minapolitan berbasis perikanan budidaya, dan

2) Mengembangkan sistem pengaturan dan pengawasan yang lebih ketat mengenai aktivitas penangkapan ikan.

Ikan cakalang (Katsuwonus pelamis) sebagai salah satu jenis dari kelompok ikan pelagis besar, merupakan suatu kegiatan ekonomi unggulan di sektor perikanan Sulawesi Utara. Namun hingga saat ini perikann ini belum memiliki daya saing yang tinggi dibandingkan dengan negara Asean lainnya, karena proses produksi belum sepenuhnya efisien. Salah satu alat tangkap yang umum digunakan oleh nelayan di Sulawesi Utara untuk mengeksplotasi sumberdaya cakalang adalah pancing huhate (pole and line).

Pelabuhan Perikanan Pantai Belang merupakan salah satu pangkalan kapal penangkap huhate yang beroperasi di perairan Sulawesi Utara dan sekitarnya. Untuk meningkatkan efisiensi penangkapan ikan dengan alat tangkap ini, maka diperlukan pengetahuan tentang sebaran daerah penangkapan ikan dan musim penangkapannya.

\section{Tujuan penelitian}

1) Memetakan posisi daerah penangkapan huhate yang didaratkan di pelabuhan Perikanan Belang.

2) Menduga musim penangkapan ikan cakalang dengan huhate.

\section{Tempat dan waktu penelitian}

Penelitian ini dilakukan di perairan Laut Maluku dan di Pelabuhan Perikanan Belang, Kabupaten Minahasa Tenggara, Provinsi Sulawesi Utara; selama Oktober sampai Desember 2012.

\section{METODE PENELITIAN}

\section{Bahan dan alat penelitian}

Bahan dan alat yang digunakan dalam penelitian terdiri dari kapal huhate (pole and line), bahan bakar, umpan hidup, alat bantu rumpon, GPS, kamera, meteran, komputer dan alat tulis menulis.

\section{Metode pengumpulan data}

Penelitian ini menggunakan metode deskriptif (Nazir, 1999; Arikunto, 1997); data primer dikumpulkan dengan cara memetakan posisi daerah penangkapan saat operasi, wawancara dan pengukuran langsung; dan data sekunder dilakukan dengan mencatat atau mengutip informasi di Pelabuhan Perikanan Belang dan instansi terkait, serta telaah pustaka yang relevan.

\section{Metode analisis data}

Data primer dan data sekunder selanjutnya diolah dengan cara memetakan posisi tangkapan cakalang yang didaratkan di pelabuhan Belang, kemudian diplot dalam peta dasar menjadi peta tematik.

Musim penangkapan ikan diduga dengan rumusan (Reppie, $d k k .$, 2011) sebagai berikut: 


$$
Y_{{ }_{j}}=\frac{1}{t} \sum Y_{i j}
$$

dimana:

$Y_{\cdot j}=$ rata-rata hasil tangkapan bulanan selama periode $t$ tahun

$\sum Y_{i j}=$ Produksi bulanan pada bulan ke-j tahun- $i$

Musim ikan dapat diketahui dengan membandingkan $Y_{\cdot j}$ dengan rata-rata hasil tangkapan total $(\bar{Y})$, dimana jika:

$Y_{\cdot j}>\bar{Y}$ berarti musim ikan

$Y_{\cdot j}<\bar{Y}$ berarti tidak musim ikan

Nilai $\bar{Y}$ dicari dengan

$$
\bar{Y}=\frac{1}{n} \sum Y_{i j}
$$

dimana $n=\Sigma n_{i}=12$ (bulan).

\section{HASIL DAN PEMBAHASAN}

\section{Deskripsi alat tangkap}

Unit penangkapan huhate oleh nelayan setempat memiliki bagian-bagian konstruksi umum, yang terdiri dari kapal, alat tangkap berupa joran, tali pancing, kail dengan umpan buatan, umpan hidup dan alat bantu penangkapan berupa rumpon.

\section{Daerah penangkapan huhate}

Daerah penangkapan ikan dengan huhate yang berpangkalan di Pelabuhan Perikanan Belang selama tahun 2012 (Gbr. 1) ialah di perairan Laut Maluku pada posisi geografi antara $0^{\circ} 00^{\prime} 5.48^{\prime \prime} \mathrm{U}$ -
$1^{0} 16^{\prime} 2.12^{\prime \prime}$ U dan $124^{0} 04^{\prime} 5.48^{\prime \prime} \mathrm{T}-126^{0} 22^{\prime} 5.38^{\prime}$, T.

\section{Hasil Tangkapan}

Data hasil tangkapan huhate yang didaratkan di Pelabuhan Perikanan Belang berdasarkan bulan selang tahun 2012 disajikan dalam Tabel 1, sedangkan berdasarkan kapal disajikan dalam Tabel 2. Jumlah tangkapan terbanyak terjadi pada bulan September kemudian diikuti bulan Agustus dan bulan Juli; sedangkan berdasarkan kapal terjadi pada KM Karunia kemudian diikuti KM Citra Bahari dan KM Aldira.

\section{Pendugaan Musim Penangkapan Ikan}

Data catch per unit effort (CPUE) dan deviasinya selama periode tersebut disajikan pada Tabel 1 diperuntukkan untuk menduga musim penangkapan ikan cakalang dengan pole and line di perairan Laut Maluku didasarkan pada rata-rata hasil tangkapan per satuan upaya bulanan selama periode waktu satu tahun.

Gambar 2 menunjukkan bahwa musim penangkapan ikan dengan huhate terjadi pada bulan April untuk fase pertama, kemudian pada bulan Juli sampai bulan September untuk fase kedua; tetapi fase kedua lebih besar dan lebih lama. Bukan musim ikan terjadi pada bulan Juni untuk fase pertama diduga terkait dengan tiupan angin selatan; sedangkan bulan November sampai bulan Maret karena mungkin juga tiupan angin barat.

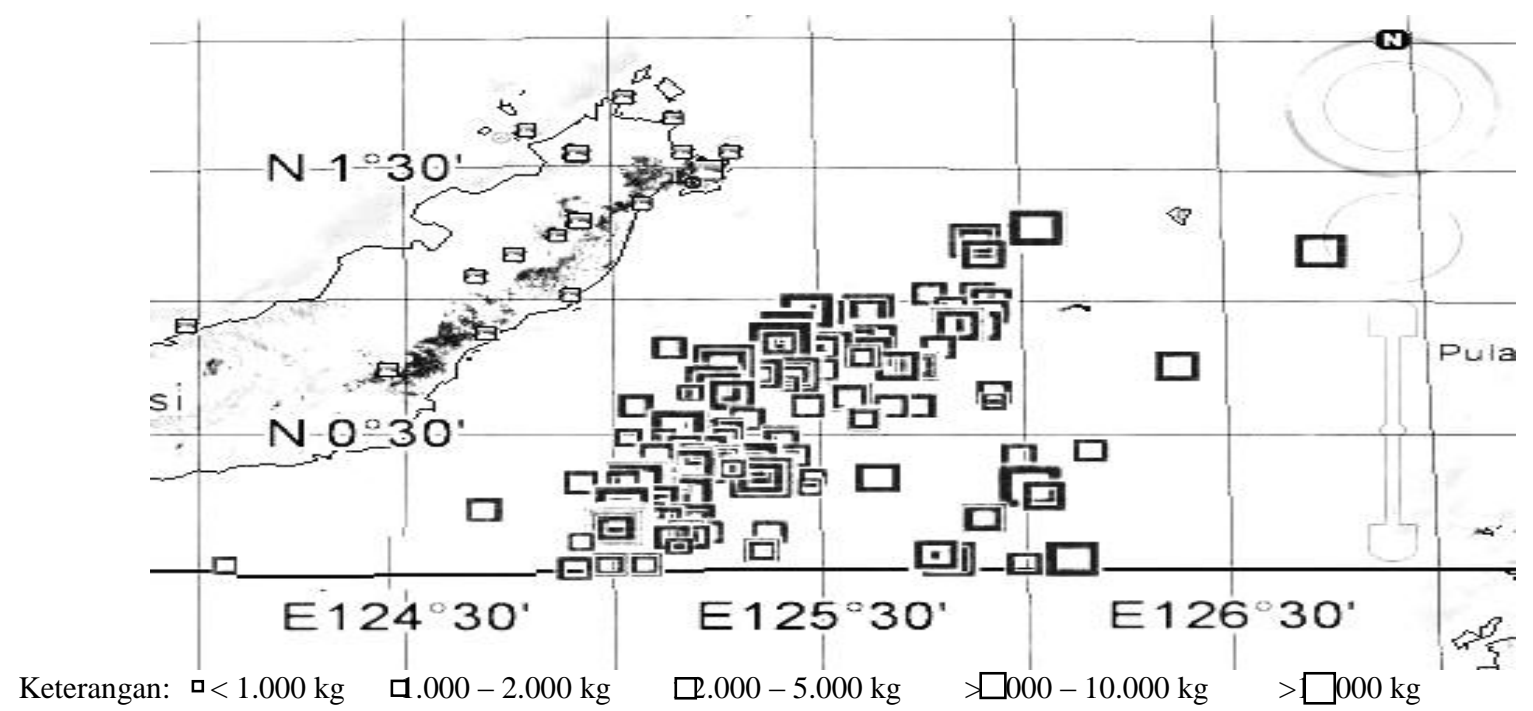

Gambar 1. Daerah penangkapan pole and liner di Laut Maluku 
D. Suprianto dkk.

Tabel 1. Hasil tangkapan pole and line bulanan yang didaratkan di Belang tahun 2012

\begin{tabular}{lcccc}
\hline \multicolumn{1}{c}{ Bulan } & Catch (ton) & $\begin{array}{c}\text { Effort X } \\
\text { (trip) }\end{array}$ & $\begin{array}{c}\text { CPUE Y } \\
\text { (ton/trip) }\end{array}$ & $(Y-\bar{Y})$ \\
\hline Januari & 15.35 & 14 & 1.10 & -0.95 \\
Februari & 28.22 & 24 & 1.18 & -0.87 \\
Maret & 26.35 & 27 & 0.98 & -1.07 \\
April & 65.57 & 29 & 2.26 & 0.30 \\
Mei & 38.20 & 23 & 1.66 & -0.38 \\
Juni & 31.97 & 23 & 1.39 & -0.65 \\
Juli & 70.95 & 23 & 3.08 & 1.04 \\
Agustus & 92.52 & 26 & 3.56 & 1.51 \\
September & 151.80 & 34 & 4.46 & 2.42 \\
Oktober & 57.56 & 32 & 1.80 & -0.25 \\
November & 41.36 & 26 & 1.59 & -0.45 \\
Desember & 22.20 & 16 & 1.39 & -0.66 \\
\hline Total & 642.05 & 297 & 24.45 & \\
\hline Rata-rata & 53.50 & 24.75 & 2.04 & \\
\hline
\end{tabular}

Tabel 2. Tangkapan pole and liner yang didaratkan di Belang tahun 2012

\begin{tabular}{lccc}
\hline \multicolumn{1}{c}{ Nama Kapal } & Catch (ton) & Effort (trip) & CPUE \\
\hline KM. Alfian Star & 57.49 & 55 & 1.05 \\
KM. Aldira 09 & 126.83 & 51 & 2.49 \\
KM. Sinar & 49.80 & 51 & 0.98 \\
KM. Berkat Usaha & 14.10 & 14 & 1.01 \\
KM. Safari & 28.88 & 33 & 0.88 \\
KM. Karunia 03 & 164.05 & 34 & 4.83 \\
KM. Lestari Indah & 44.15 & 40 & 1.10 \\
KM. Citra Bahari 03 & 156.76 & 19 & 8.25 \\
\hline Jumlah & 642.05 & 297 & 20.57 \\
\hline Rata-rata & 80.26 & 37.13 & 2.57 \\
\hline
\end{tabular}

Sumber: Pos Pengawasan SDKP Belang tahun 2012

\section{Pembahasan}

Pada bulan Januari hanya 4 buah kapal yang beroperasi; kemungkinan hal ini dipengaruhi oleh kondisi laut yang bergelombang (angin barat). Hal ini diindikasikan dengan rendahnya total tangkapan selama tahun itu yaitu hanya 15,35 ton. Daerah penangkapan ikan yang terjauh sekitar 90,3 mil laut (lama tempuh 9 jam), sedangkan yang terdekat 41,3 mil laut (lama tempuh 4,1 jam).
Pada bulan Februari kapal yang beroperasi sebanyak 6 kapal; daerah penangkapan ikan yang terjauh sekitar 76,97 mil laut (lama tempuh 7,6 jam), sedangkan yang terdekat 31,23 mil laut (lama tempuh 3,1 jam). Kapal yang beroperasi pada bulan Maret sebanyak 6 kapal; daerah penangkapan ikan yang terjauh sekitar $70.51 \mathrm{mil}$ laut (lama tempuh 7,5 jam), sedangkan yang terdekat 31,17 mil laut (lama tempuh 3,1 jam). 


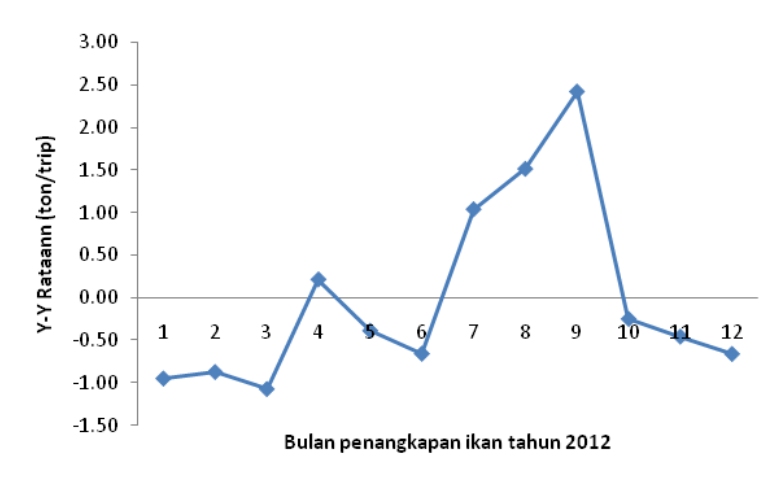

Gambar 2. Musim penangkapan ikan dengan pole and line diperairan Laut Maluku tahun 2012

Pada bulan April kapal yang beroperasi sebanyak 7 kapal; daerah penangkapan ikan yang terjauh sekitar 89.75 mil laut (lama tempuh 8,9 jam), sedangkan yang terdekat 23,33 mil laut (lama tempuh 2,3 jam). Bulan Mei sebanyak 7 unit kapal yang beroperasi dengan daerah penangkapan ikan yang terjauh sekitar 107,44 mil laut (lama tempuh $10,7 \mathrm{jam}$ ), dan yang terdekat $41,06 \mathrm{mil}$ laut (lama tempuh 4 jam).

Terdapat 6 unit kapal yang beroperasi pada bulan Juni, dan daerah penangkapan ikan yang terjauh sekitar 94,53 mil laut (lama tempuh 9,4 jam), yang terdekat sejauh 32,01 mil laut (lama tempuh 3,2 jam). Pada bulan Juli kapal yang beroperasi sebanyak 7 kapal; daerah penangkapan ikan yang terjauh sekitar 92,25 mil laut (lama tempuh 9,2 jam), sedangkan yang terdekat 34,15 mil laut (lama tempuh 3,4 jam).

Pada bulan Agustus kapal yang beroperasi sebanyak 8 kapal; daerah penangkapan ikan yang terjauh sekitar 94,53 mil laut (lama tempuh 9,4 jam), sedangkan yang terdekat 33,4 mil laut (lama tempuh 3,3 jam).

Bulan September kapal tercatat sebanyak 8 unit kapal yang beroperasi; pada bulan ini total hasil tangkapan ikan terbanyak yaitu 151,80 ton, daerah penangkapan ikan yang terjauh sekitar 101,55 mil laut (lama tempuh 10,1 jam), sedangkan yang terdekat 23,79 mil laut (lama tempuh 2,3 jam). Pada bulan Oktober kapal yang beroperasi sebanyak 8 kapal; daerah penangkapan ikan yang terjauh sekitar 89,5 mil laut (lama tempuh 8,9 jam), sedangkan yang terdekat 33,08 mil laut (lama tempuh 3,3 jam).

Pada bulan November kapal yang beroperasi sebanyak 8 kapal; daerah penangkapan ikan yang terjauh sekitar 135,0 mil laut (lama tempuh 13,5 jam), sedangkan yang terdekat 36,8 mil laut (lama tempuh 3,6 jam). Pada bulan Desember kapal yang beroperasi sebanyak 7 kapal; daerah penangkapan ikan yang terjauh sekitar 99,28 mil laut (lama tempuh 9,9 jam), sedangkan yang terdekat 38,5 mil laut (lama tempuh 3,8 jam).

Berdasarkan data tersebut di atas maka secara umum, daerah penangkapan ikan dengan huhate yang berpangkalan di Pelabuhan Perikanan Belang sepanjang tahun 2012 berada di perairan Laut Maluku, bagian timur perairan Belang; dengan jarak terjauh sekitar135,0 mil laut dari Pelabuhan Belang dan jarak terdekat 23,8 mil laut. Jika kecepatan kapal rata-rata 10 knot, maka jarak terjauh dapat ditempuh selama 13,5 jam dan jarak terdekat selama 2,4 jam. Hal ini berarti bahwa apabila daerah penangkapan dekat dengan pangkalan, maka operasi penangkapan dapat dilakukan dengan one day trip; tetapi jika daerah penangkapan ikan jauh dari pangkalan, maka operasi penangkapan dapat dilakukan selama 2 atau 3 hari untuk satu trip, tergantung pada kondisi laut dan keberadaan ikan.

Berdasarkan CPUE pada masing-masing kapal, KM Citra Bahari 03 memiliki CPUE yang tertinggi $(8,25)$, kemudian diikuti KM Karunia 03 $(4,83)$, dan KM Aldira 09 (2,49). Hal ini disebabkan karena KM Citra Bahari berukuran terbesar, kemudian diikuti secara berturut-turut oleh kedua kapal yang lainnya. Karena kapal berukuran besar, maka daya muat umpan hidup lebih banyak dan hari operasi yang lebih lama dalam satu trip.

\section{KESIMPULAN}

Berdasarkan hasil penelitian maka dapat disimpulkan bahwa daerah tangkapan ikan dengan huhate yang berpangkapan di Pelabuhan Belang berada di Laut Maluku, pada posisi geografis antara 0000'5.48" LU - 1016'2.12" LU dan $124004{ }^{\prime} 5.48^{\prime}$ ' BT - 126022'5.38' BT. Musim penangkapan ikan dengan huhate pada tahun 2012 terjadi pada bulan April untuk fase pertama, kemudian pada bulan Juli sampai bulan September untuk fase kedua; tetapi fase kedua lebih besar dan lebih lama.

\section{DAFTAR PUSTAKA}

Anonimous. 2008. Buku Petunjuk Teknis (Juknis) Penangkapan Ikan Ramah Lingkungan. DKP, Jakarta. 
D. Suprianto dkk.

Anonimous. 2011. Masterplan Percepatan dan Perluasan Pembangunan Ekonomi Indonesia. Kementerian Koordinator Bidang Perekonomian.

Anonimous. 2012. Laporan Rekapitulasi Kedatangan dan Keberangkatan Kapal Perikanan di Pelabuhan Belang. Pos Pengawasan SDKP Belang.

Arikunto, S. 1997. Prosedur Penelitian. PT. Rineka Cipta, Jakarta.
Nasir, M. 1999. Metode Penelitian. Edisi ke-4. Ghalia, Indonesia.

Reppie, E., E.P. Sitanggang, dan J. Budiman. 2011. Pendugaan potensi dan musim penangkapan ikan julungjulung (Hemirhamphus sp.) berdasarkan hasil tangkapan soma giop di perairan Selat Bangka, Kabupaten Minahasa Utara, Sulawesi Utara. Pacific Journal Regional Board of Research North Sulawesi 1(6):1010-1014. 